\title{
CORRECTION
}

\section{Correction to: Radiation exposure for intraoperative 3D scans in a hybrid operating room: how to reduce radiation exposure for the surgical team}

\author{
Published online: 17 February 2022 \\ (c) CARS 2022

\section{Correction to: \\ International Journal of Computer Assisted Radiology \\ and Surgery (2018) 13:1291-1300 \\ https://doi.org/10.1007/s11548-018-1747-1}

K. Schuetze ${ }^{1}$ (1) $\cdot$ M. Kraus ${ }^{2} \cdot$ A. Eickhoff ${ }^{1} \cdot$ F. Gebhard ${ }^{1} \cdot$ P. H. Richter ${ }^{1}$

The original version of this article unfortunately contained an error. Raffael Cintean's contributions to this work were not acknowledged in the article. The authors would like to acknowledge the contributions of Raffael Cintean, who has assisted in clinical trial planning, acquiring the data and writing and correcting parts of the final paper.

Publisher's Note Springer Nature remains neutral with regard to jurisdictional claims in published maps and institutional affiliations.

The original article can be found online at https://doi.org/10.1007/ s11548-018-1747-1.

$\triangle$ K. Schuetze

konrad.schuetze@uniklinik-ulm.de

1 Department of Trauma-, Hand- and Reconstructive Surgery,

Ulm University, Albert-Einstein-Allee 23, 89081 Ulm,

Germany

2 Department of Orthopaedic Surgery, Ulm University, Oberer Eselsberg 45, 89081 Ulm, Germany 